\title{
MENTE HUMANA Y VOLUNTAD
}

\author{
Jesús de Garay \\ Universidad de Sevilla
}

Resumen: Frente al tradicional análisis de la mente humana como inteligencia, se defiende la consideración de la voluntad como componente esencial de la mente humana. En concreto se estudia el origen de la distinción entre naturaleza y voluntad, a partir de algunos textos de Aristóteles, Plotino, Agustín de Hipona y Anselmo de Canterbury.

Palabras clave: Mente humana, voluntad, Aristóteles, Plotino, Agustín de Hipona, Anselmo de Canterbury.

\section{Human mind and will}

Abstract: Faced with the traditional analysis of the human mind as intelligence, the consideration of the will is defended as an essential component of the human mind. In particular, the origin of the distinction between nature and will is studied, based on some texts by Aristotle, Plotinus, Augustine of Hippo and Anselm of Canterbury.

Keywords: Human mind, Will, Aristotle, Plotinus, Augustine of Hippo, Anselm of Canterbury.

Recibido: 16/01/2019 Aprobado: 20/02/2019

\section{Introducción}

¿Qué es lo propiamente humano? Dice Aristóteles que nadie quiere ser feliz si es al precio de dejar de ser quien es. ¿Cuándo dejamos de ser humanos y cuándo dejamos de ser nosotros mismos? Quizá el homúnculo fabricado por Wagner, el discípulo de Fausto, sea humano: piensa, siente, se emociona, incluso sufre porque su corporalidad se reduce a ser sólo un líquido en una probeta. ¿Acaso el soporte físico es indiferente para ser humano? Entonces, como afirmaban los pitagóricos, ¿̇sería cierto que el alma 
puede transmigrar de unos cuerpos a otros? Quizá un soporte informático puede cumplir esa función. En tal caso, mi cuerpo no sería constitutivo de mi humanidad. Y si no en el cuerpo, ¿dónde poner la esencia de lo humano? ¿En las emociones? ¿En la conciencia? Pero ya también Aristóteles advierte de que hay una conciencia sensible que compartimos los humanos con los animales ${ }^{1}$. Sea como sea, parece ineludible plantear qué rasgos definen a la mente humana, que la distinguen de otros organismos y de otras mentes.

Es obvio que el asunto no es claro. Y ciertamente hay muchos candidatos para definir a la mente humana. Quizá la inteligencia —y más específicamente la conciencia- es lo que solemos caracterizar principalmente como mente humana. Si 'mente humana' significa conciencia, entonces la inteligencia artificial sería un posible futuro candidato para formar parte de los humanos. Es decir, si la mente humana se define por la inteligencia consciente, y si fuera posible llegar a construir una conciencia artificial, entonces cuál sea el soporte físico resulta indiferente. Y sin duda, la conciencia parece una candidata plausible para definir la mente humana.

Dicho de otro modo: es claro que podemos construir artificialmente inteligencia. Al menos algunas funciones intelectuales, como el procesamiento de datos, la memoria, y funciones cada vez más complejas, como la creatividad. La búsqueda se orienta ahora hacia la tecnología capaz de construir conciencia. Si estas expectativas están fundadas, el tiempo lo dirá; y entonces sabremos (sabrán) si el homúnculo de Fausto era o no una fantasía sin fundamento.

No obstante, quizá la búsqueda de conciencia artificial deja sin explorar otro rasgo no menos relevante de la mente humana: la voluntad. Es decir, la definición de 'mente humana' remite no sólo a las emociones y a la conciencia, sino también y esencialmente a la voluntad libre. La cuestión entonces sería: ¿es posible construir una libre voluntad artificial?

${ }^{1}$ Cfr. Acerca del alma, III-2. Cfr. también Alejandro de Afrodisias, Acerca del alma, 65,2-10. 
Este breve escrito no pretende resolver esa pregunta, sino que tiene un alcance mucho más modesto. Simplemente analiza algunos momentos determinantes de la historia de la noción de voluntad: cómo surge y evoluciona hasta convertirse en un constitutivo esencial de la mente humana. En concreto, me limitaré a revisar someramente algunos textos, frecuentemente desatendidos, de Plotino ${ }^{2}$, Agustín ${ }^{3}$ y Anselmo ${ }^{4}$. Esta breve historia de la voluntad culmina con la contraposición entre la libertad de la voluntad y la necesidad de la naturaleza, de tal modo que si la voluntad fuese independiente de la naturaleza, entonces se cerraría la posibilidad de construir artificialmente la voluntad ${ }^{5}$.

\section{La voluntad en Platón y Aristóteles}

Frecuentemente, y con razón, se suele considerar a Platón y al platonismo como exponentes del racionalismo (conocimiento de sí, teoría de las Ideas, intelectualismo socrático, racionalización de la política, dialéctica, matemáticas...). Pero quizá se descuida la importancia del platonismo en la caracterización de la voluntad. Sin embargo, paradójicamente es en la tradición platónica donde aparece y se desarrolla la noción de voluntad.

\footnotetext{
${ }^{2}$ Enéadas VI-8

${ }^{3}$ De libero arbitrio III

${ }^{4}$ De concordia III

${ }^{5}$ Esta argumentación ofrece alguna similitud con la que plantea la independencia de la conciencia con respecto a la naturaleza física, y que concluye con la independencia de la conciencia con respecto a la materia. Esta argumentación es repetida frecuentemente por los comentadores de Aristóteles en el siglo VI. Cfr. Por ejemplo, Filopón, De intellectu, 21,318; Simplicio, In libros Aristotelis De anima commentaria, 188,11-12; Esteban, en: Ioannis Philoponi in Aristotelis De anima libros commentaria, 466,46-467,7. En síntesis, el argumento dice así: la conciencia se define como un volver sobre sí misma; pero la materia se define como extensión de partes extra partes, y por tanto la materia es incapaz de volver sobre sí misma; en consecuencia materia y conciencia son irreductiblemente diferentes. He analizado con más detalle lo relativo a la conciencia en La unidad de la conciencia en los comentadores griegos de Aristóteles, Contrastes XXII, n. 3 (2017), pp. 51-74
} 
Como es bien sabido, Platón, y en general el platonismo, subraya la importancia del conocimiento de sí. Proclo, un platónico del s.V d.C. afirma: "El principio de la filosofía y de la enseñanza de Platón es el conocimiento de sî”. En el Fedón, Sócrates argumenta en favor de la independencia del alma respecto al cuerpo, rechazando por ejemplo la tesis de que el alma sea la armonía del cuerpo: el alma, dice, no es armonía porque se opone y manda sobre las afecciones del cuerpo (94be). De ahí que la filosofía sea una preparación para la muerte en tanto es un entrenamiento para que el alma se acostumbre a vivir separada del cuerpo (67e): se trata de que el alma quede a solas consigo misma (65d), se concentre en sí misma (83a) y se reconozca idéntica consigo misma (80ab). En síntesis, Platón insiste en que la primera exigencia de la filosofía es que el alma (la mente) se conozca sí misma.

En numerosos lugares Platón establece el papel directivo de la razón, así como el carácter subsidiario, pero no menos esencial, de las pasiones (thymós y epithimía). Pero además, por ejemplo en el Simposio, añade (205a) que lo que mueve al alma es el amor al bien y a la belleza. Este amor es un deseo de un bien que en parte falta, y en parte ya se posee. Es una voluntad (boúlesis), un querer el bien.

Aristóteles continúa la indagación platónica, mediante el análisis de lo espontáneo o voluntario (hekoúsion), que define como "aquello cuyo principio está en uno mismo y que conoce las circunstancias concretas de la acción"”. Es decir, lo voluntario o espontáneo es un acto realizado sin coacción exterior y con conocimiento. Esta espontaneidad voluntaria, señala Aristóteles, se da tanto en el ser humano como en los demás animales. En cambio, son exclusivas de la acción humana tanto la deliberación racional (boulé) como la elección consiguiente (proaíresis) ${ }^{8}$. Por otra parte, lo voluntario, la deliberación y la elección se subordinan al deseo del bien, como

${ }^{6}$ In Alcibiades. 5,15-16.

${ }^{7}$ Cfr. Ética a Nicómaco III, 1, 1111a 22-24.

${ }^{8}$ Cfr. Ética a Nicómaco III, 2-5. 
Platón ya había mostrado. No obstante, Aristóteles matiza la sugerencia platónica, concretando ese deseo de bien en los bienes aparentes y en la felicidad. En cualquier caso, y siguiendo la estela platónica, Aristóteles caracteriza la voluntad (boúlesis) como deseo (órexis $)^{9}$, y específicamente como deseo racional ${ }^{10}$ de los bienes. "La elección (proaíresis) es o inteligencia deseosa (orektikós noûs) o deseo inteligente (órexis dianoetiké), y esta clase de principio es el hombre" ${ }^{11}$.

\section{La voluntad en Plotino}

Plotino ocupa sin duda un lugar protagonista en la tradición platónica en tanto establece los elementos centrales del denominado 'neoplatonismo'. Algunas de sus doctrinas serán rectificadas por otros neoplatónicos, como Porfirio o Jámblico, pero dentro de una tradición común. En particular, los escritores neoplatónicos mantendrán siempre la afirmación plotiniana de que el principio primero de todo lo real es un Uno o Bien trascendente, que está por encima de la inteligencia y lo inteligible.

No obstante, hay un rasgo original en Plotino que no parece haber tenido especial eco en la tradición neoplatónica posterior. En la clasificación de las Enéadas, elaborada por Porfirio, casi como colofón de toda la reflexión plotiniana, está la Enéada VI-8, donde Plotino caracteriza al Uno como voluntad (thélema, hekoúsion).

Como es sabido, para Plotino lo Primero de la realidad no es susceptible de ninguna denominación, porque en tanto es la unidad de todo lo real, excluye cualquier nombre que lo situaría en contraposición con los demás nombres. De ahí la constante disculpa de Plotino por intentar poner un nombre a esa unidad primera: uno, bien, voluntad, primero, principio... Una y otra vez reconoce que estas denominaciones son engañosas. No obstante,

${ }^{9}$ Cfr. Acerca del alma, 433a 23-24: "La volición (boúlesis) es deseo (órexis)". Cfr. también 414b. 2: "El deseo consiste en apetencia (epithymía), impulso (thymós) y voluntad (boúlesis)".

${ }^{10}$ Cfr. Acerca del alma, III, 7-11.

${ }^{11}$ Cfr. Ética a Nicómaco, VI-2, 1139b 4-6. 
a pesar de estas constantes rectificaciones, analiza cada una de estas denominaciones, y también la denominación de lo Primero como voluntad en la mencionada Enéada VI-8.çç

Para contextualizar esta tesis de Plotino del Uno como Voluntad libre, conviene recordar que, en el conjunto de la doctrina plotiniana hay una constante afirmación de la libertad humana: "El alma humana, mientras está en el cuerpo, es dueñísima de sí misma, es libre (eleuthéra) y está fuera de la causalidad cósmica" (III-1, 8, 9-10). En particular Plotino rechaza diversas posiciones estoicas que supondrían la negación de la libertad humana:

Un principio que eslabona y concatena, por así decirlo, todas las cosas unas con otras, y confiere a cada una su modo de ser, un principio que se supone es uno solo, y a partir del cual se llevan a cabo todas las cosas en virtud de unas razones seminales [...]. Esta teoría comporta una forzosidad universal y absoluta (III-1, 7, 1-9)

Es preciso, insiste Plotino, distinguir dos clases de acciones humanas, las involuntarias, que están causadas desde fuera de nosotros, y las voluntarias. Las acciones voluntarias se pueden caracterizar del siguiente modo:

Cuando se tiende a algo poniéndose bajo el mando de la propia razón pura (lógon katharón) e impasible, entonces hay que decir que ésta es la única tendencia que está a nuestro arbitrio y es voluntaria (eph' hemin kai hekoúsion) y que esa es nuestra obra, la que no nos vino de fuera, sino de dentro, de un alma pura, de un principio que es nuestro guía y señor principal (III-1, 9, 10-14).

Es decir, para Plotino el ser humano es libre en tanto que tiene dentro de sí un principio que es "guía y señor principal" de nuestras acciones, que parece consistir en "la razón pura e impasible" (lógon katharón kai apathé). Sin embargo, para Plotino la razón pura no puede ser el principio primero de nuestras acciones, ya que lo Primero de cualquier realidad (incluido lo primero del ser humano) es voluntad y no razón. Consecuentemente, la 
unidad del alma, el uno en mí, que regula toda mi actividad, no es inteligencia sino voluntad (thélema). Frente al Uno, la Inteligencia es sólo una segunda hipóstasis para Plotino y todo el neoplatonismo.

El argumento clásico del neoplatonismo para relegar a la inteligencia y lo inteligible a un segundo plano es conocido: lo inteligible es plural, hay muchas ideas, y por lo tanto no puede identificarse con la unidad primera que rige nuestros actos. Además, entender es siempre entender algo, por lo que siempre persiste una alteridad entre el entender y lo entendido. Incluso en el entender que se entiende hay una dualidad entre el entender que entiende y el entender entendido.

Por encima de la inteligencia, en VI-8 la unidad primera es caracterizada como potencia infinita, causa sui (aition heatwn: VI-8, 14, 41), el bien mejor de todos, productor ("su ser es engendrar") y autosuficiente, puesto que no depende de nada más que de sí mismo. Todos estos rasgos inducen a Plotino a denominar 'voluntad' a esa unidad primera que rige todo lo real. El ser humano no escapa a esa primacía del Uno o Voluntad. Ese Uno o Voluntad es el principio primero de cualquier realidad, también del ser humano. Y por tanto es lo primero que nos define a cada uno de nosotros. Ciertamente es sólo un nombre, y por tanto equívoco porque se distingue de los demás nombres y en consecuencia implica diferencia, lo mismo que sucede con los nombres de 'uno' o 'bien'. Pero, dejando de lado las limitaciones del lenguaje, Plotino subraya que lo primero del alma humana, su unidad primera, no es tanto la inteligencia sino la voluntad.

Esta voluntad está más allá de la necesidad. "Lo primero no es por necesidad (ex anánkes), pues en él no existía la necesidad. La necesidad está en los seres que siguen al principio" (VI-8, 9, 11-12). Voluntad se contrapone a necesidad, y en particular a la necesidad de la razón, de la verdad y de la naturaleza. La verdad es necesaria: por ejemplo, si una ley física es verdadera, necesariamente es así. No puede no ser. "La verdad es un dios segundo" (V-5, 3, 2-4). Pero "lo primero es rey de la verdad" $(\mathrm{V}-5,3,18)$. "Lo enteramente simple y autosuficiente no necesita nada para ser. Lo segundo es también autosuficiente, pero está necesitado de sí mismo, pues 
tiene necesidad de pensarse a sí mismo" (V-3, 13, 16-19). "El dios Cronos está encadenado, obligado a permanecer siempre idéntico a sí mismo" (V$8,13,1)$.

Para Plotino la voluntad no sólo se opone a la necesidad, sino con mucho mayor motivo se opone al azar. Azar implica causas externas, pero la voluntad depende exclusivamente de sí misma. Es causa sui, en el sentido de que no hay ninguna causa externa que la determine. Sin duda, la necesidad y el azar determinan la conducta humana. Pero, en tanto que el ser humano es voluntad, en esa misma medida es independiente de la necesidad y del azar.

Es conveniente, sin embargo, hacer una precisión. La doctrina de la voluntad aparece claramente expuesta en VI-8 para caracterizar al Uno en sí o Dios primero. Pero cuando Plotino analiza las funciones o facultades del ser humano, la voluntad humana (thélema) no aparece subrayada con la misma fuerza. ¿Cómo hay que interpretar entonces la prioridad de la voluntad en el ser humano, a la luz de los textos de Plotino?

Los rasgos propios de lo Primero por supuesto han de caracterizar lo primero del ser humano, en tanto que lo Primero de todo lo real es también lo primero del ser humano. En consecuencia, la unidad del hombre es un poder, una potencia activa: una fuerza que es productiva porque está engendrando vida y obras constantemente. Y desde luego, tal como decía Aristóteles, la unidad del ser humano es un principio que está en sí mismo, cuya actividad procede de sí mismo, en tanto que excluye cualquier coacción externa.

Plotino, en cualquier caso, se mantiene fiel a las indicaciones tanto de Platón como de Aristóteles. Lo primero del alma humana es deseo. Deseo del bien. Un deseo del Bien, en estricto platonismo, o un deseo de felicidad y de bienes aparentes en la interpretación aristotélica. Este deseo del bien es el que rige cualquier acción humana. La conclusión para Plotino es que la voluntad humana (lo primero del alma) debe ser concebida primariamente como deseo. Es decir, la voluntad, ese poder que está en nosotros mismos, que dirige todo nuestro obrar y que se mueve sólo por sí mismo, eso es el deseo. Y concretamente un deseo del bien. Voluntad es deseo. 
No obstante, frente a Aristóteles, Plotino no deja de subrayar la prioridad de la voluntad (el deseo) frente a la inteligencia, en tanto el deseo es previo a la conciencia intelectual. El deseo es inconsciente. Nosotros no queremos el bien sólo de modo consciente, sino lo queremos aunque no tengamos conciencia de ello. La conciencia es sólo un estado secundario del hombre. Lo que mueve y dirige nuestra actividad no es la conciencia ni la razón, sino el deseo inconsciente de bien.

En cualquier caso, la voluntad humana adolece de la limitación del ser humano. Los rasgos propios de la Voluntad Primera aparecen aminorados en el ser humano. En especial, la prioridad de la Voluntad Primera sobre la necesidad no queda ya claramente subrayada en la voluntad humana o deseo. Porque el deseo humano es necesario: necesariamente queremos el bien. No podemos no quererlo, como no podemos no querer ser felices.

La libertad de la necesidad —característica esencial de la Voluntad Primera-, sin embargo, aparece en el hombre como libertad de elección (proaíresis). En tanto tenemos libertad de elección, en esa misma medida estamos libres de la necesidad. "El hombre libre es causa de sí mismo", decía Aristóteles (Metafísica, I-2, 982b 26): somos libres en tanto actuamos espontáneamente sin coacción, siendo exclusivamente nosotros mismos la causa de nuestras acciones. Esta libertad de elección es consciente: requiere conocimiento de sí y de las circunstancias particulares de la acción.

Ahora bien, la libertad de elección, en tanto elige entre opciones diferentes, en esa medida es una imperfección, es decir, no puede ser la unidad primera del ser humano. Porque además depende de opciones externas a sí misma, por lo que no es independiente ni propiamente causa sui. Por consiguiente, la libertad de elección está subordinada al deseo necesario del bien.

En síntesis, según Plotino lo que define al alma humana (a la mente humana, si se prefiere) es primariamente la voluntad y no la inteligencia. Esta voluntad hay que interpretarla como deseo inconsciente y necesario del bien. La voluntad humana también se manifiesta como libertad de elección, que sí es consciente, pero que está subordinada a este deseo 
inconsciente y necesario del bien. De este modo, Plotino se mueve dentro del análisis aristotélico, en tanto que el deseo del fin es necesario, mientras que la libertad de elección delibera y elige entre los medios apropiados para el fin.

\section{La voluntad en Agustín de Hipona}

El protagonismo de la voluntad reaparece un siglo después en los análisis agustinianos. No es claro hasta qué punto Agustín conoció la Enéada VI-8. Consta el impacto que sufrió al conocer los escritos de los platónicos, y sin duda estaba al tanto de las reflexiones de Plotino y Porfirio. En cualquier caso, Agustín fue un pensador original dentro de la tradición platónica, también por su compromiso teológico cristiano. Por lo demás resulta forzado caracterizarlo simplemente como neoplatónico, ya que algunas de sus doctrinas se ajustan más al platonismo medio.

Sea como sea, de acuerdo con la tradición neoplatónica, también sus reflexiones se orientan hacia el análisis de la experiencia interior de la conciencia y hacia la caracterización de la mente (mens) humana, siempre en busca de la unidad primera del alma humana. Es conocido el trasfondo teológico de sus análisis de la mente humana: sus consideraciones más detalladas se encuentran en De Trinitate, donde examina la mente humana en tanto es imagen de la Trinidad. Pero ese trasfondo teológico no impide que su análisis de la mente humana sea directamente fenomenológico, en tanto se esfuerza en mostrar cómo la mente aparece inmediatamente en nuestra experiencia.

Con respecto a Plotino, cabe resumir en pocas palabras el planteamiento de Agustín: la voluntad humana se distingue de la inteligencia pero también del deseo del bien. Además, la voluntad es conceptualizada sólo como una facultad del alma humana junto con la inteligencia y la memoria, pero no como la unidad primera del alma. 
Agustín toma como punto de partida la presencia inmediata de la mente a sí misma. En esa inmediatez de la autopresencia de la mente, aparece ya la voluntad (De Trinitate, X, 9, 12 y X, 10, 13):

Cuando se dice a la mente «conócete a ti misma», al momento de oír 'a ti misma', si lo entiende, ya se conoce, no por otra razón sino porque está presente a sí misma [...]. Entonces sabe que quiere y conoce igualmente que nadie puede querer si no existe y vive. Asimismo refiere su querer a algo que quiere mediante la voluntad.

Es decir, la existencia de la voluntad no es una teoría filosófica o religiosa, sino una realidad que se presenta inmediatamente a la mente humana. Cabe ciertamente que sea una ilusión, pero el mismo Agustín subraya que si es una ilusión, entonces cualquier otro conocimiento también lo es porque presupone la autopresencia de la mente y de la voluntad. "No hay nada que sienta tan firme y tan íntimamente como que tengo voluntad" (De libero arbitrio, III, 1, 3).

Por lo demás, la voluntad aparece como un poder muy propio de cada uno de nosotros. Ya Epicteto, y en general la tradición estoica, había insistido en la importancia de distinguir entre lo que está en nuestro poder y lo que no lo está: lo que no está en nuestro poder ha de permanecer al margen de nuestras preocupaciones, pues sucederá necesariamente al margen de lo que decidamos; por el contrario, afirmaba Epicteto, debemos centrar nuestra atención en lo que está en nuestro poder.

Agustín caracteriza precisamente a la voluntad como aquello que está en nuestro poder. Más aún, la voluntad es un poder que está en poder de sí mismo. "Nuestra voluntad no sería voluntad si no estuviera en nuestro poder. Y por lo mismo que está en nuestro poder, por eso es libre" (De libero arbitrio, III, 3, 8). Es decir, por una parte la voluntad es un poder que puede sobre otros poderes, como la facultad de la vista, de la imaginación, etc.: el ver o no ver está en nuestro poder, como también el atender a algo o no, el desplazarnos de lugar o no. Pero más allá de ser un poder que puede sobre 
otros poderes, es también un poder que puede sobre sí mismo: es decir, el querer de la voluntad puede querer o no querer.

Agustín intenta subrayar que la voluntad, de algún modo, es un poder que puede sobre sí mismo. La reflexión no es sólo un rasgo de la autoconciencia intelectual sino también de la voluntad. Pero no en términos de autopresencia, sino de autoposesión, de autodominio. La voluntad vuelve sobre sí misma, en tanto que puede sobre su mismo poder. En este sentido, la voluntad se autorregula, se autodetermina: es autónoma. La voluntad se marca a sí misma a qué, dónde, cuándo y cómo aplicar su querer. La voluntad no sólo dirige y determina a los otros poderes del alma y del cuerpo, sino que además —y previamente — se gobierna y se determina a sí misma.

De este modo la voluntad se muestra en Agustín como uno de los elementos definitorios de la propia singularidad. Define aquello que somos en propiedad, junto con la autoconciencia intelectual y la memoria. La mente humana (mens) se configura así no solamente como un conjunto de poderes de memoria o de racionalidad, sino además como autoposesión de la voluntad.

Esta voluntad es concebida por Agustín como voluntad libre, capaz de libertad de elección. Y, frente a Plotino, es además interpretada como una perfección, y no como una limitación del ser humano.

Si el hombre en sí es un bien y no puede obrar rectamente sino cuando quiere, síguese que necesariamente ha de tener voluntad libre, sin la cual no se concibe que pueda obrar rectamente [...]. La voluntad libre es uno de los bienes que proceden de Dios (De libero arbitrio, II, 1, 3).

O de otro modo, es mejor el ser humano con voluntad libre que sin ella. Incluso en la situación obvia de que yerra y elige frecuentemente lo que es perjudicial para él. Se trata de un poder superior al poder de una piedra o de otros animales, que no tienen posibilidad de equivocarse en su conducta, ya que siempre actúan de acuerdo con sus tendencias o deseos naturales. "El movimiento de la piedra es natural y el del alma voluntario" (De libero arbitrio, III, 1, 2). 
Porque, así como es mejor un caballo que se desvía del camino que una piedra, que no se desvía, porque carece de sentido y de movimiento propio, así también es más excelente la criatura que peca por su propia y libre voluntad que aquella otra que es incapaz de pecar por carecer de voluntad libre (De libero arbitrio, III, $5,15)$.

En resumen, la voluntad libre se distingue del deseo natural y muestra una mayor perfección. Es decir, la libertad de la voluntad se contrapone a la necesidad de la naturaleza. Esto implica que la voluntad y la naturaleza implican cursos causales diferentes. La causalidad de la voluntad no es la causalidad de la naturaleza.

-Tú me preguntas por la causa de la misma voluntad; y si llegara a encontrarla, ¿no me preguntarías también por la causa de esa causa? [...]. — Si la voluntad fuera conforme a la naturaleza, la conservaría y no le sería nociva [...]. - Pero ¿cuál puede ser la causa de la voluntad anterior a la misma voluntad? [...]. No me explico por qué tú te empeñas en buscar esta causa fuera de la voluntad (De libero arbitrio, III, 17, 48-49).

La voluntad es la única causa de sus actos. El argumento es precisamente que puede oponerse a las tendencias naturales. Si fuera natural el movimiento de la voluntad del mal, entonces querría necesariamente el mal. Es decir, la voluntad es causa de determinaciones que no están en la naturaleza. Gracias a la voluntad, aparecen en el mundo determinaciones, realidades que no estaban dadas por la naturaleza.

Nada está tanto en nuestro poder como nuestra misma voluntad, pues ella está dispuesta a la ejecución sin demora absolutamente ninguna en el mismo instante en que queremos. De aquí que con razón podamos decir que envejecemos por necesidad y no por voluntad, e igualmente que morimos por necesidad, no por voluntad, y así de otras cosas semejantes (De libero arbitrio, III, 3, 7). 
La voluntad libre, por consiguiente, aparece en Agustín como causa libre independientemente de la causalidad necesaria de la naturaleza. Ahora bien, en tanto que Dios crea la Naturaleza de modo voluntario, entonces hasta la misma necesidad de la naturaleza depende de la voluntad (en este caso de la voluntad de Dios). Por eso, Agustín puede afirmar que "no hay más causas eficientes de todo lo que sucede que las voluntarias" (De civitate Dei, $\mathrm{V}, 9,4)$.

En conclusión, si comparamos los planteamientos de Agustín con los de Aristóteles o Plotino, en Agustín aparece la voluntad libre como un rasgo esencial de la mente humana, distinto de la inteligencia y de la memoria. Ahora bien, en Agustín ¿dónde queda el deseo natural, que tanto en Aristóteles como en Plotino constituye un rasgo esencial del alma humana? La respuesta está en la memoria. Y aquí Agustín sí se muestra claramente como neoplatónico.

"Nos hiciste para ti y nuestro corazón está inquieto hasta que descanse en ti" (Confesiones I, 1, 1). "Tú eres más interior que lo más íntimo mío" (Confesiones III, 6, 11). Es decir, independientemente de la autoconciencia intelectual y de la autoposesión de la voluntad, hay una tercera dimensión de la mente humana que es inconsciente y que determina necesariamente al ser humano hacia el bien. Este bien primero para Agustín es Dios y también se corresponde con la felicidad aristotélica: encontrar (recordar) a Dios equivale a encontrar la felicidad.

De este modo, la voluntad libre queda subordinada al deseo necesario y natural de Dios y de felicidad. Es decir, Dios y la felicidad es el fin de la voluntad. Ciertamente la voluntad es una perfección, es autónoma y se autorregula, pero sólo encuentra su plena perfección en tanto se adecúa a un fin dado, natural y necesario, que se manifiesta como un deseo que rige toda nuestra acción. En esta perspectiva, los planteamientos de Agustín no difieren tanto de los de Plotino y Aristóteles, recuperando el protagonismo del deseo natural por delante de la voluntad libre. 
Mente humana y voluntad

\section{La voluntad en Anselmo de Canterbury}

Ciertamente las reflexiones de Agustín acerca de la voluntad suponen una rectificación sustancial de las posiciones de Aristóteles y de Plotino. Sin embargo, el discurso de Agustín acerca de la voluntad varía notablemente de acento en función de los debates que acomete a lo largo de su vida. Al comienzo de su actividad filosófica, De libero arbitrio forma parte de su argumentación más global contra el maniqueísmo. Y en este escrito es donde se encuentran por primera vez las indicaciones más claras acerca de la voluntad. Años después Agustín no se desviará de la doctrina sobre la voluntad que ahí expone, pero la irrupción del pelagianismo le obligará a matizar su posición, destacando no tanto el papel de la voluntad humana sino más bien la primacía de la voluntad divina y de la gracia. En consecuencia, su doctrina primera sobre la voluntad parece como diluida en el contexto antipelagiano donde el protagonismo corresponde a la gracia y no tanto a la voluntad humana.

Siglos después, Anselmo de Canterbury recupera la doctrina de Agustín sobre la voluntad ${ }^{12}$. Y lo hace en su estilo característico: escritos breves y originales, con una argumentación clara, centrados en una única cuestión. Por un lado, Anselmo reafirma puntos centrales de Agustín sobre la voluntad. Por otro lado, en su afán de clarificación, corrige y desarrolla la doctrina de Agustín.

Siguiendo a Agustín, Anselmo subraya que la voluntad es un bien, una perfección, independientemente de que sea buena o mala: "La buena voluntad no es más que la mala voluntad, ni ésta es más el mal que aquélla el bien" (De casu diaboli, c.8): el ser de la voluntad es el mismo, independientemente de que sea una voluntad buena o mala. Todo lo que es, es bueno, en tanto ha sido creado por Dios. También por tanto la voluntad. Asimismo la voluntad es una facultad distinta de otras facultades del ser humano ${ }^{13}, \mathrm{y}$

${ }^{12}$ En particular en De veritate, De libertate arbitrii, De casu diaboli, De concordia praescientiae et praedestinationis et gratiae Dei cum libero arbitrio.

${ }^{13}$ Cfr. De concordia, III, 11. 
se caracteriza por su espontaneidad, es decir, porque no tiene más causa que ella misma. ¿Por qué quiso el ángel apartarse de la justicia? "Por ninguna otra causa más que porque quiso: (non nisi quia voluit). La misma voluntad fue causa eficiente para sí y también efecto, si puede hablarse asî́" (De casu diaboli, 27). La voluntad, en tanto que voluntad, sólo depende de sí misma. "No se puede querer contra la propia voluntad (invitus), porque no es posible querer no queriendo querer" (De libertate arbitrii, 5).

También, en la línea de Agustín, subraya con especial energía la oposición entre voluntad y necesidad. Ciertamente, por ejemplo, el caballo por naturaleza (naturaliter) está sometido a la necesidad (necessitate) del deseo de comer. En cambio, el ser humano, cuando rechaza lo que le conviene o lo que debe, no actúa ni por naturaleza (non naturaliter) ni por necesidad (ex necessitate), sino porque consiente por su voluntad (volens consentiat) ${ }^{14}$.

Igualmente de acuerdo con Agustín, afirma que el ser humano está ordenado al bien, y por tanto también la voluntad está orientada al bien. Hay una finalidad para la voluntad, una rectitud de la voluntad (rectitudo): cfr. De veritate, c.4. Es decir, para Anselmo como para Agustín la voluntad no carece de referencia, no actúa de forma arbitraria, sino que su acción está orientada hacia el bien.

Aquí, sin embargo, aparece la diferencia más patente entre ambos autores. Para Agustín, el fin del hombre puede caracterizarse como el bien de la felicidad, que coincide con Dios como el bien primero. Anselmo, por el contrario, sitúa el bien de la felicidad en un lugar subordinado. Es decir, la finalidad de la voluntad no es la felicidad sino la justicia. Dicho de modo simplista, Anselmo no es eudaimonista, Agustín sí. O también, la felicidad es el bien natural del ser humano; en cambio, la justicia es el bien moral. Es decir, la voluntad quiere necesariamente la felicidad, mientras que está en su poder querer o no la justicia. Pero en cualquier caso, ambos bienes, felicidad y justicia, están dados a todo ser humano. En términos agustinianos o

${ }^{14}$ Cfr. De libero arbitrio, c. 5. 
platónicos, Anselmo podría decir que tenemos siempre memoria tanto de la felicidad como de la justicia.

Anselmo sistematiza estas consideraciones en De concordia III, 11:

La voluntad puede significar equívocamente tres cosas: el instrumento (instrumentum) de querer, la afección (affectio) del instrumento y el uso (usus) del mismo. El instrumento de querer es esa fuerza del alma de la que nos servimos para querer $[\ldots]$. La afección de este instrumento es aquello por lo cual este instrumento es afectado para querer algo, aun cuando no piense lo que quiere [...]. Así, el instrumento de querer es afectado a querer la salud aun cuando no piensa en ello [...]. En cambio, nunca se sentirá afectado a querer la enfermedad $[\ldots]$. También de modo semejante en el hombre justo el instrumento es afectado para querer la justicia aun durante el sueño, hasta el punto que, cuando le viene el recuerdo de la justicia, inmediatamente la ama. En cambio, el uso del instrumento no lo tenemos más que cuando pensamos lo que queremos.

Es decir, 'voluntad' se dice en tres diferentes sentidos: como instrumento, como affectio y como uso. Como instrumento, equivale a la facultad de la voluntad, por la que podemos querer. Como affectio o aptitudo la voluntad está ya determinada a querer unos bienes u otros, aun cuando no piense en ellos, como cuando está dormido. La voluntad como uso se refiere a la voluntad que quiere con conciencia y conocimiento y, en este sentido, puede hablarse de libertad de arbitrio o libre elección, en tanto que sólo denominamos 'libre' a aquellas acciones que realizamos conscientemente y con conocimiento de la acción y de las posibles opciones. En cierto modo, esta triple distinción se relaciona con la distinción aristotélica entre facultad, hábito y acto, pero referida ahora exclusivamente a la voluntad e interpretada de un modo original.

La voluntad como instrumento se da siempre en el ser humano y se caracteriza por poder mover todos los demás instrumentos humanos (facultades) así como otros instrumentos externos, como una pluma o un hacha. En contraste con los demás instrumentos, la voluntad se mueve a sí 
misma (instrumentum se ipsum movens). No obstante, la voluntad como instrumento requiere estar determinada por sus affectiones: sin ellas, la voluntad no hace nada (nihil facit).

Ahora bien, según Anselmo, mientras que la voluntad como instrumento es una y la misma para todos los hombres, por el contrario la voluntad como afección es doble. Hay dos (y sólo dos) affectiones en la voluntad: la affectio commodi y la affectio iustitiae (la voluntad de felicidad y la voluntad de justicia).

Una afección (affectio commodi) es para querer lo útil, la otra (affectio iustitiae) para querer lo recto, porque la voluntad como instrumento no quiere nada más que esas dos cosas. Si se inclina hacia alguna otra cosa, es por razón de la utilidad o de la rectitud [...]. Mediante la afección de querer lo útil, el hombre quiere siempre la felicidad y ser feliz; mediante la afección de querer la rectitud, quiere la rectitud y ser justo (III-11).

Ahora bien, la voluntad de felicidad es inseparable (inseparabilis) del ser humano: no podemos no querer ser felices. Es una inclinación natural y necesaria. Y en función de ella, la voluntad organiza los bienes, en tanto procuran o impiden dicha felicidad. La affectio commodi es así voluntad de lo ventajoso, de lo útil para nuestra felicidad.

Por el contrario, la voluntad de justicia es separable (separabilis) del ser humano, en cuanto podemos querer la justicia o no (III-12). Es decir, mientras que necesariamente tenemos la voluntad de felicidad, por el contrario tenemos la voluntad de justicia sólo si libremente la queremos. Por ello, la voluntad de justicia es la misma justicia (voluntas quidem iustitia est ipsa iustitia), mientras que la voluntad de felicidad no es la felicidad (III-13). La voluntad de justicia implica querer la justicia por sí misma (propter se ipsam), esto es, no como útil para la felicidad o para nuestro interés sino de modo desinteresado. Aunque, matiza Anselmo, se puede querer lo útil y la felicidad, no por su exclusivo interés sino porque está ordenado a lo justo. 
Por último, conviene integrar estas consideraciones en el horizonte de la definición que Anselmo da de la libertad: "potestas servandi rectitudinem voluntatis propter ipsam rectitudinem" (De libertate arbitrii, c.3). La libertad, como la voluntad, es un poder, una fuerza: potestas. Y de acuerdo con el esquema de Anselmo, en primer lugar la voluntad como instrumento es un poder de autodeterminación, una fuerza para autodeterminarse en un sentido o en otro, siendo en cierto modo causa sui, que es tanto causa eficiente como efecto, instrumentum se ipsum movet. En segundo lugar, la voluntad como affectio es también un poder, una fuerza para determinarse necesariamente hacia todo aquello que nos procure la felicidad.

Esta fuerza de voluntad es especialmente manifiesta cuando aparece el conflicto entre la voluntad de felicidad y la voluntad de lo justo: que la voluntad de felicidad sea dominada por la voluntad de justicia exige una potestas, una fuerza mayor, que el solo orientar el poder de la voluntad hacia lo ventajoso. De este modo, la voluntad moral de la justicia es un poder mayor que la voluntad natural de felicidad, en tanto supone enfrentarse y dominar a inclinación natural a lo útil y la felicidad. Y en este sentido, la voluntad del mal es una debilidad de la voluntad.

\section{A modo de epílogo}

Giertamente no termina en Anselmo la historia de la voluntad. Hasta nuestros días, han sido y son muchos los autores que tratan de explicar la presencia de nuestros actos voluntarios. Más recientemente, basta pensar en Nietzsche y otros intérpretes suyos como Heidegger o Deleuze. En cualquier caso, la historia de la voluntad comienza muchos siglos antes.

Pero lo decisivo hoy no es tanto la cuestión historiográfica, sino la realidad de nuestros actos voluntarios. Sin duda, cualquier intento de definir la mente humana exige la experiencia interior y subjetiva. Pero no es válido el argumento de que esa experiencia, por ser subjetiva, es incomunicable. Porque todas las experiencias, incluidas las experiencias objetivas y externas, son subjetivas e interiores. Medir también es una experiencia subjetiva. 
Por consiguiente, cabe definir (intentar definir) la mente humana a partir de las experiencias comunes de los seres humanos. Y entre esas experiencias comunes (comunicables y comunicadas) están los actos voluntarios. Cualquier legislación (y cualquier insulto) da por supuesta la realidad de los actos voluntarios.

$\mathrm{El}$ argumento de que no se pueden hipostasiar los actos voluntarios en una misma función (la voluntad) es un argumento débil. Siempre que observamos que se repite regularmente un mismo fenómeno, todos atribuimos esos repetidos fenómenos a un mismo poder. Y damos un nombre a ese poder. En este caso 'voluntad'. La dificultad vendrá después, al examinar si esa voluntad tiene consistencia propia o deriva de otros poderes o procesos previos. Pero lo que en ningún caso puede hacerse es obviar la presencia reiterada y universal de los actos voluntarios. Otra cosa es una metafísica precipitada.

Señaladas estas precisiones, cabe afirmar que la voluntad pertenece esencialmente a la definición de mente humana. Y que por tanto cualquier intento de fabricar artificialmente mente humana ha de concluir en la fabricación de voluntad artificial, y no sólo de inteligencia artificial.

Ahora bien, el intento de fabricar voluntad artificial a partir de componentes naturales choca con los análisis filosóficos que afirman la radical separación de la naturaleza y la voluntad. Por tanto, si en algún momento se llegase a producir voluntad humana a partir de procesos físicos, quedarían descartados tales análisis filosóficos. O Anselmo o voluntad artificial.

\section{Bibliografía empleada}

Agustín de Hipona, Obras, Madrid, BAC, 1946, 22 vols.

Alejandro de Afrodisias, Acerca del alma, Gredos, Madrid, 2013.

Anselmo de Canterbury, Obras completas, Madrid, BAC, 1952, 2 vols.

Aristóteles, Acerca del alma, Madrid, Gredos, 1994.

Aristóteles, Ética a Nicómaco, Instituto de Estudios Políticos, Madrid, 1970.

J. de Garay, "La unidad de la conciencia en los comentadores griegos de Aristóteles", en: Contrastes, 2017 (XXII, 3): 51-74 
Mente humana y voluntad

Juan Filopón, In Aristotelis De anima libros commentaria, Berlín, Academiae Litterarum Regiae Borussicae, 1897.

Plotino, Enéadas, Madrid, Gredos.

Proclo, In Alcibiades.

Simplicio, In libros Aristotelis De anima commentaria, Berlín, Academiae Litterarum Regiae Borussicae, 1882.

Jesús de Garay

jgaray@us.es 